\title{
El periodista científico y el psicólogo de la comunicación: su papel en la transmisión de mensajes científicos a través de los medios de comunicación de masas
}

\author{
Juana María Gila Ordóñez \\ Fátima Rodríguez Barrera \\ Dra. Ana Guil Bozal \\ Dpto. de Psicología Social \\ Universidad de Sevilla
}

RESUMEN

La proliferación de MCM unido al aumento del nivel cultural de la población, posibilitan y hacen necesario un acercamiento del científico a la sociedad. En nuestro trabajo presentamos algunas de las, a nuestro juicio, más importantes estrategias necesarias para llevar a cabo esta compleja tarea de acercamiento del mundo académico al hombre de la calle, mediante el trabajo interdisciplinardedos profesionales: el/la periodista científic@yel/la psicólog@de la comunicación.

\section{ABSTRACT}

The proliferation of MCM, together with the increasins cultural level of the man in the street, make it not only posible but necessary to bring sciencie closer to the public. Two professionals fron different disciplines, one a scientific journalist, the other a social psychologist whose research covers the field of communication, have studied the problem. In the work, we propose what we believe to be some of the more important strategies that must be carried out in oder to accomplish the complex task of bringing the academic world closer to the people.

Palabras claves: Ciencia/Periodismo/Psicología/Comunicación/Mensajes.

Key Words: Science/Journalism/Psychology/Communication/Messages.

\section{INTRODUCCIÓN}

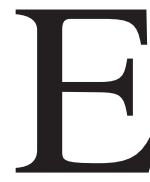

1 conocimiento científico ha permanecido tradicionalmente encerrado en los centros de investigación, dándose a conocer al gran público sólo después de muchas aplicaciones prácticas, pasados varios años desde su descubrimiento y siempre con mucha cautela ante el posible mal uso de la información especializada. Y aunque muchas de estas 
240 El periodista científico y el psicólogo de la comunicación: su papel en la transmisión de mensajes científicos a través de los medios de comunicación de masas

precauciones hayan de seguir siendo mantenidas, el crecimiento de los MCM unido al del nivel cultural de la población, posibilitan y hacen necesario una mayor apertura y un mayor acercamiento del científico a la sociedad.

El Congreso Nacional sobre «Comunicar la ciencia en el siglo XXI», celebrado en Granada del 25 al 27 de Marzo de 1999, fue el primer Congreso Nacional sobre Comunicación Social de la Ciencia, que tuvo como objetivo general -en palabras del presidente andaluz Chaves- «analizar y debatir las fórmulas y estrategias más adecuadas para difundir y hacer más accesible el conocimiento científico, entre sectores sociales que hasta ahora permanecían alejados del mismo».

A raíz de aquí surgió la idea de profundizar en la relación entre ciencia y medios de comunicación. Para ello proponemos partir del rol del Periodista Científico en relación con el Psicólogo Social de la Comunicación, trabajando ambos en la divulgación de la ciencia a través de los Medios de Comunicación de Masas.

\section{EL PERIODISTA CIENTÍFICO Y EL PSICÓLOGO DE LA COMUNICACIÓN}

Divulgar el conocimiento científico de forma amena y adecuada a los diversos tipos de audiencia, es un paso bastante mas complicado de lo que pudiera parecer a primera vista.

«El problema radica en cómo se traslada este conocimiento a la sociedad, sobre todo en un contexto comunicativo en el que lamentablemente prima lo espectacular e incluso el sensacionalismo, sobre los criterios que definen una correcta información y divulgación científica: la simbiosis entre amenidad y rigor» (Vladimir de Semir, 1999).

Consideramos que en este proceso de comunicación de contenidos científicos, el Psicólogo Social podría jugar un importante papel, desarrollando en concreto varios tipos de intervenciones:

- Como Comunicador o experto en estrategias de comunicación, consciente de las dificultades y de las especiales condiciones necesarias para que se produzca esta comunicación de la manera mas correcta (intereses de los emisores, características del medio y del canal y características de los receptores), habría de analizar en cada caso cuáles son las metodologías específicas para paliar estas posibles interferencias.

- Como Mediador, tendría la misión fundamental de actuar de nexo entre el científico y el periodista. En muchas ocasiones el científico no es todo lo buen comunicador que cabría desear, porque no es ésta su especialidad. En paralelo, el periodista sabe comunicar pero no tiene porqué entender los contenidos que ha de 
transmitir, no está capacitado para discriminar entre lo esencial y lo accesorio, no conoce las posibles repercusiones de su información, recoge opiniones no siempre avaladas por especialistas, etc... Este desfase contribuye a confundir a la opinión pública y a devaluar la propia investigación científica. Por eso ambas partes -científico y periodista- necesitan de ese intermediario que pueda facilitar la relación, acercando sus distintas perspectivas, en beneficio siempre del usuario de los medios.

- Como Formador del periodista especializado en comunicar la ciencia, el psicólogo social tiene también una función docente esencial, consecuencia directa de su doble especialidad -científica y comunicadora- y de su papel de mediador entre estos dos importantes grupos profesionales.

Se trata en definitiva de acercar la ciencia al individuo concreto y a la sociedad en general, utilizando tantos caminos como sea posible, hasta llegar al ideal de ciencia al servicio de toda la comunidad.

Respecto al periodista científico y siguiendo a Quiroga (1999), éste es a su vez un mediador entre los distintos segmentos sociales, teniendo como función primordial la producción de información pública útil para el ejercicio de la ciudadanía y para una mejor calidad de vida. El periodista que se ocupa de temas científicos, es además una especie de institución en la sociedad civil, constituyéndose en empresa prestadora de un servicio público esencial.

\section{LA COMUNICACIÓN SOCIAL}

$\mathrm{Al}$ analizar la comunicación a través de cualquier medio, un paso previo es obviamente partir de cuáles son los elementos básicos de todo proceso de comunicación social. Siguiendo a León, Gómez y Barriga (1996) recogemos estos elementos y una conceptualización general del proceso de comunicación, en la que se parte de una definición en términos de conjunto dinámico de relaciones entre elementos que interaccionan y se influyen mutuamente. Porque la naturaleza de la comunicación social sólo puede conocerse considerando su complejidad procesual. Por lo tanto, al hablar de comunicación social, se está haciendo referencia además de a un proceso de interacción mutua, a un proceso de influencia social.

Podríamos distinguir siete pasos y un elemento adicional, que se dan en todo proceso de comunicación social:

En relación con quién inicia la comunicación, con el emisor:

1. Motivación previa de querer decir algo.

2. Selección de código y canal, qué lenguaje y qué medio se va a utilizar.

3. Codificación, cómo estructurar la información en un sistema común de interpretación con el receptor. 
242 El periodista científico y el psicólogo de la comunicación: su papel en la transmisión de mensajes científicos a través de los medios de comunicación de masas

Relacionados con quién recibe el mensaje, con el receptor:

4. Percepción, atención y contacto, para poder captar los aspectos esenciales del mensaje, teniendo en cuenta que la información asimilada será mucho menor que la percibida, en función de múltiples variables individuales.

5. Selección de los mensajes en función de los posibles niveles de aceptación del receptor

6. Decodificación o consideración de la capacidad del receptor de traducir $\mathrm{y}$ entender el mensaje

7. Efectos del Mensaje, es decir, que posibles cambios provocará en el receptor

Y vinculando a ambos integrantes de la comunicación: emisor y receptor

8. Retroalimentación o feedback, que informa al emisor del efecto de su mensaje en el receptor e intercambia sus papeles, facilitando con ello que la comunicación sea efectiva al convertirse realmente en un acto de comunicación y no en una simple emisión de información.

En relación a la comunicación social de la ciencia, Rial y Señor (1999) señalan que para que sea eficaz dicha comunicación, ha de implicar necesariamente códigos de intercambio inteligibles tanto respecto al mensaje, como respecto a quienes lo reciben. Solo es posible proponer métodos eficientes si se conocen con detalle tanto el objeto que comunicamos -la ciencia en este casocomo los receptores del mensaje.

Es importante también filtrar algunos mensajes de los MCM, por ejemplo en el caso de la utilización de la ciencia ficción, horóscopos, mundo de lo oculto y pseudociencias en general, que utilizan para atraer al público una información llamemosle mágica más que lógica y racional y por lo tanto, alejada de la ciencia. Porque este tipo de mensajes, sin duda produce influencias en el público. Y son los científicos y comunicadores sociales los responsables de dar la voz de alarma para evitar equívocos.

Gámez, Toro, y Armentia (1999), exponen al respecto que «quienes están vinculados con la comunicación social de la ciencia no pueden permanecer al margen de este fenómeno, todo lo contrario, son precisamente quienes pueden aportar racionalidad al mismo».

De todo lo anterior se deriva la gran importancia de la formación especializada del profesional, o equipo de profesionales, que hayan de actuar de emisores de la información científica, en su proceso de transmisión social. 


\section{LOS MCM COMO TRANSMISORES DE LA CIENCIA}

«Los mensajes mediáticos a través de los MCM son artefactos que gobiernan nuestra sensibilidad, nuestros saberes, nuestras emociones. Son mediadores entre las personas y están ahí para modelarlas y provocar tareas conjuntas" (Pérez, 1998).

\section{III.1. TRADICIONALES: PRENSA, RADIO, TV Y CINE}

Haciendo referencia a la divulgación de la ciencia a través de la pequeña pantalla, León (1999), observa que hay cadenas de televisión que olvidan alguna de las tres funciones que la UNESCO señala: información, entretenimiento y educación. Porque el objetivo de los productores de TV, no es transmitir un conjunto de conocimientos teóricos que permitan un entendimiento profundo de cuestiones científicas y técnicas, sino construir discursos que mantengan a la audiencia frente a la pantalla, apelando al interés práctico y a las emociones del público.

Pese a esto, en la historia de la TV destaca el trabajo de algunos divulgadores que han logrado construir enunciados que resultan de gran interés para el público, sin perder en absoluto el necesario rigor científico. Divulgadores de reconocido prestigio como David Attenborough, Carl Sagan, Jacques Cousteau o Félix Rodríguez de la Fuente son claros ejemplos.

Ademas de la TV, la prensa ha contribuido desde sus orígenes a la divulgación científica tanto desde columnas especializadas, como desde artículos escritos directamente por los propios investigadores, o a través de entrevistas a los mismos, e incluso mediante la publicación periódica de revistas de divulgación al estilo, por ejemplo, de Muy interesante o Quo. E igualmente la radio de manera similar a la TV y la prensa y el cine, tanto en su vertiente mas cercana a la realidad, como de ciencia ficción.

Mediante el estudio de los recursos comunicativos empleados por todos estos medios se puede profundizar en la naturaleza misma de la divulgación científica a través de los medios audiovisuales, e igualmente se pueden extraer algunas conclusiones generales sobre cuáles son las formas mas eficaces de hacerlo.

Pero sin duda son en la actualidad los gabinetes de comunicación y especialmente la información obtenida a través de Internet, los medios de comunicación que están adquiriendo un papel prioritario, al influir además a su vez en la divulgación del resto de medios.

\section{III.2. NUEVOS MEDIOS DE COMUNICACIÓN.}

\section{III.2.1. GABINETES DE COMUNICACIÓN.}

Los gabinetes de comunicación son departamentos de reciente creación, nacidos con el objetivo de hacer llegar la información de una organización, 
244 El periodista científico y el psicólogo de la comunicación: su papel en la transmisión de mensajes científicos a través de los medios de comunicación de masas

institución o estamento desde dentro hacia fuera. En nuestro caso se trataría de dar a conocer al gran público, los resultados que se producen en los centros de investigación.

El gabinete de comunicación ha de actuar a modo de visagra entre el científico y los medios de comunicación, haciendo de traductor y transmisor de una información muy especializada, destinada a un publico objetivo cada vez más interesado y cada vez más exigente (Rojas y Calvo, 1999).

\section{III.2.2. INTERNET}

La década de los 90 ha presenciado el resurgimiento de un nuevo tipo de periodismo científico, favorecido por la expansión de Internet, que nació como un medio de intercambio de información entre científicos. Realmente la comunicación a través de Internet está modificando muchos hábitos de nuestra sociedad, tanto en los aspectos laborales como culturales y de empleo del tiempo de ocio.

El aumento de información disponible para los periodistas a partir de la creación de Internet, es considerado por algunos un progreso absoluto. Pero otros temen que junto al incremento cuantitativo de la información, pueda producirse un deterioro cualitativo de ésta.

La irrupción en las páginas de los periódicos de información obtenida a través de Internet, también plantea nuevas exigencias a reporteros y editores, a la vez que supone el desarrollo de nuevas estrategias de interpretación y evaluación por parte de los lectores (Cendón, Corchete, Martín, Nú ez, Ruiz e Yriart, 1999).

\section{PATROCINIO Y FINANCIACIÓN}

El patrocinio de la ciencia en los distintos medios de comunicación es una forma de filtrar el conocimiento científico que llega hasta el público.

«En las emisoras tanto de radio como de TV, la vía del patrocinio es probablemente la única que puede fomentar la presencia de la ciencia continuada. Un panorama desolador que en el caso del negocio privado sólo podría ser corregido por vía patrocinio o publicidad directa, pero que en el caso de la radio y televisiones públicas nacionales o autonómica- resulta intolerablemente escandaloso» Toharia (1999).

Realmente el patrocinio actúa de filtro de la información pero además, también la financiación de la investigación va a filtrar el qué y quién investiga. Normalmente se financian proyectos que responden a lineas de investigación señaladas específicamente en una política determinada, dejando de lado todo lo que no encaje dentro de estas prioridades. El investigador no trabaja pues guiado por sus conocimientos o por su intuición. En muchas ocasiones lo hace en función 
de que el proyecto sea supceptible de obtener financiación, ya que sin ella no sería posible en la mayoría de los casos su realización.

Igualmente se financia a unos investigadores y a otros no según variables ideológicas, de política departamental, etc., independientemente de la calidad e innovación de unos investigadores sobre otros, quizás no tan bien relacionados. Con ello se quedan muy buenos proyectos en el camino, al no tener apoyo de profesionales influyentes.

Sería importante peritar estas políticas de financiación para que realmente se apoyen proyectos de calidad, revisados por expertos interdisciplinares e independientes, que puedan de la manera mas objetiva posible valorar la viabilidad de los mismos.

\section{ALGUNAS ESTRATEgIAS ÚTILES PARA LA TRANSMISIÓN DE MENSAJES CIENTÍFICOS}

\section{V.1. EQUIPOS INTERDISCIPLINARES.}

En la actualidad el trabajo individual va quedando reducido a espacios muy concretos, dando paso, poco a poco, a los equipos de trabajo. Equipos multidisciplinares, que al reunir a distintos especialistas, profundizan mas en las cuestiones llegando a producir un trabajo de mayor calidad, en mucho menos tiempo.

Un aspecto básico para hacer llegar la información científica hasta el gran público, es contar con un equipo interdisciplinar de profesionales capacitados para seleccionar y codificar adecuadamente el contenido a transmitir, elegir el medio adecuado y considerar el resto de variables a controlar hasta conseguir que el mensaje llegue a buen fin.

Estos equipos estarían formados por diversos especialistas, dependiendo del área científica concreta a la que pertenezca la información. Incluyendo entre ellos, de manera prioritaria, al periodista científico y al psicólogo de la comunicación, que como ya hemos comentado mas arriba, son quienes han recibido una formación profesional básica mas adecuada para ello.

\section{V.2. USO DEL PENSAMIENTO ANALÓGICO.}

Los MCM utilizan técnicas narrativas muy diferentes a las empleadas por la ciencia. Habitualmente el lenguaje científico ofrece explicaciones exhaustivas, amplias, sistemáticas y a la vez específicas y concretas sobre las materias objeto de su estudio. El lenguaje periodístico, sin embargo, es mucho mas rápido y recurre con frecuencia a estrategias sensacionalistas, utilizando en otras un lenguaje de índole poético y/o dramático.

«El pensamiento analógico puede eliminar muchas barreras de comunicación. Con relación a la ciencia y a las analogías, los editores que trabajan 
en periódicos diarios tienden a ignorar el valor de las analogías para explicar ideas complicadas, aunque la comparación entre un concepto abstracto y una situación concreta comprobadamente facilite la comprensión de noticias sobre descubrimientos científicos. Por otro lado, algunos redactores utilizan estas figuras del lenguaje tan intuitivamente que se olvidan de sus limitaciones o dejan de aprovechar sus incontadas posibilidades como herramienta de expresión, no sólo para aclarar temas difíciles sino también para añadir "imágenes" es decir, representación pictóricas a los textos» (Dallanho, 1999).

Efectivamente el lenguaje analógico puede ser una ayuda muy eficaz que sirva de puente entre el científico y el hombre de la calle, que no sólo tiene derecho, sino que también necesita un acercamiento a esos conocimientos. Porque la necesidad de saber esta en la base misma del desarrollo humano, formando parte de nuestros mecanismos adaptativos. Entre ellos las percepciones atributivas de causalidad, que en palabras de Heider -estudioso pionero de las mismas- no son mas que una forma de «procedimiento científico del hombre de la calle», que necesita conocer aquello que esta distante y para ello realiza inferencias sobre el porqué de determinados fenómenos, llegando incluso a inventar sus propias explicaciones con tal de no quedar en la incertidumbre y la indefensión que produce la falta de conocimiento.

Pues bien, el uso de analogías es un excelente recursos precisamente para acercar ideas, realidades lejanas, que difícilmente podríamos conocer de manera directa al no disponer entre nuestras estrategias explicativas de elementos suficientes de comprensión.

Las analogías pueden entenderse como una forma primitiva de obtener conocimientos, mucho menos precisa que el conocimiento deductivo, pero mucho mas abierta a la creatividad individual. El pensamiento analógico es de hecho un pensamiento anterior evolutivamente al pensamiento racional en el desarrollo del ser humano, tanto a nivel filogenético como ontogenético.

El uso de analogías, metáforas, parábolas, cuentos, etc... ha sido de hecho un recurso utilizado con frecuencia por educadores en general, profesores, maestros, padres..., para introducir en conceptos complejos, a quienes aún no tenían la formación suficiente como para abordarlos de manera directa.

\section{V.3. OTRAS ESTRATEGIAS.}

La existencia de múltiples medios de comunicación, ha facilitado al usuario la posibilidad de elegir el medio mas idóneo para ellos, a través del cuál prefieren ser informados. Hay personas que leen los diarios, revistas especializadas, otras escuchan la radio, se conectan a Internet, ven la televisión o asisten a conferencias, parques temáticos o palacios de congresos, a contemplar en directo las novedades 
que pueden ofrecerles. Y en la mayoría de los casos utilizan distintos medios de manera conjunta. Por eso la información científica ha de seguir también estos distintos cauces, si pretende llegar a grandes sectores de la población.

Es también clave no olvidar que la comunicación sin feed-back, sin retroalimentación que nos informe sobre cómo llegó el mensaje y cuál es el punto de vista del receptor, deja de ser comunicación para convertirse en un simple proceso de transmisión de información. Hoy día, cualquier medio de comunicación que se precie de serlo, tiene en cuenta este hecho e incorpora siempre el camino de vuelta en sus programaciones, utilizando a su vez esta información para modificar, reconvertir, etc... y seguir planificando futuras actuaciones, de manera acorde con las demandas del público.

\section{Bibliografía:}

- BENITO, A. (1991): Diccionario de Ciencias y Técnicas de Comunicación. Madrid: Ediciones Paulinas.

- CENDÓN, S; CORCHETE, G; MARTÍN, S; NÚ EZ, S; RUIZ, D e YRIART, F. (1999): "El impacto de internet sobre el periodismo científico en España". Actas del Congreso COMUNICAR LA CIENCIA EN EL SIGLO XXI. Pg. 207. Granada, 25, 26 y 27 de Marzo. Parque de las Ciencias y Proyecto Sur de Ediciones.

- CHAVÉS, M, (1999): Presentación del libro de Actas del Congreso COMUNICAR LA CIENCIA EN EL SIGLO XXI. Granada, 25, 26 y 27 de Marzo. Parque de las Ciencias y Proyecto Sur de Ediciones.

- DALlanHO, H, (1999): "Cómo facilitar el entendimiento de noticias sobre la ciencia a través de las analogías". En Actas del Congreso COMUNICAR LA CIENCIA EN EL SIGLO XXI. Pág. 198. Granada, 25, 26 y 27 de Marzo. Parque de las Ciencias y Proyecto Sur de Ediciones.

GÁMEZ,L, A; TORO, V Y ARMENTIA, J, (1999). "Ciencia y medios de comunicación ante las pseudociencias (o que hacer cuando aterrizan los marcianos...)". En Actas del Congreso COMUNICAR LA CIENCIA EN EL SIGLO XXI. Pg. 58. Granada, 25, 26 y 27 de Marzo. Parque de las Ciencias y Proyecto Sur de Ediciones.

- LEÓN, J.M. BARRIGA, S, GÓMEZ, T y GONZÁLEZ, B, (Coords.) (1996): "Comunicación Social" en Psicología social: una guía para el estudio. Kronos. Sevilla.

- LEÓN, B. (1999): "El documento televisivo como medio de divulgación científica". Actas del Congreso COMUNICAR LA CIENCIA EN EL SIGLO XXI. Granada, 25, 26 y 27 de Marzo. Pg. 206. Parque de las Ciencias y Proyecto Sur de Ediciones.

- MORENO, G. (1983): Introducción a la Comunicación Social actual. Madrid: Playor. 
248 El periodista científico y el psicólogo de la comunicación: su papel en la transmisión de mensajes científicos a través de los medios de comunicación de masas

- PÉREZ, J.M. (coord.) (1998): “¿Qué es consumir medios de comunicación?. Claves para su comprensión". En revista Comunicar. Monográfico sobre Educación del consumidor en Medios de Comunicación. Junta de Andalucía.

- QUIROGA. S.R. (1999): "El periodismo científico y la nueva producción del conocimiento". En Actas del Congreso COMUNICAR LA CIENCIA EN EL SIGLO XXI. Pg. 209. Granada, 25, 26 y 27 de Marzo. Parque de las Ciencias y Proyecto Sur de Ediciones.

- RIAL, A. y SEÑOR, B. (1999): "Comunicadores de la ciencia en los medios audiovisuales. El proceso creativo como común origen de la ciencia y la comunicación". En Actas del Congreso COMUNICAR LA CIENCIA EN EL SIGLO XXI. Pg. 200. Granada, 25, 26 y 27 de Marzo. Parque de las Ciencias y Proyecto Sur de Ediciones.

- ROJAS, F y CALVO, A, (1999): "Comunicación de instituciones científicas". En Actas del Congreso COMUNICAR LA CIENCIA EN EL SIGLO XXI. Pg. 50. Granada, 25, 26 y 27 de Marzo. Parque de las Ciencias y Proyecto Sur de Ediciones.

- VLADIMIR DE SEMIR, (1999): “¿Periodismo científico o trivialización de la ciencia?”. En Actas del Congreso COMUNICAR LA CIENCIA EN EL SIGLO XXI. Pg. 44. Granada, 25, 26 y 27 de Marzo. Parque de las Ciencias y Proyecto Sur de Ediciones. 